\title{
Cortical Lesion-Induced Visual Hemineglect Is Prevented by NMDA Antagonist Pretreatment
}

\author{
Huai Jiang, Barry E. Stein, and John G. McHaffie \\ Department of Neurobiology and Anatomy, Wake Forest University School of Medicine, Winston-Salem, North Carolina 27157-1010
}

Large unilateral visual cortex lesions produce enduring contralesional visual orientation deficits. To examine whether glutamate excitotoxicity is involved in establishing these deficits, cats were pretreated with the NMDA receptor antagonist dizocilpine (MK-801) $30 \mathrm{~min}$ before unilateral visual cortex ablation. Pretreated MK-801 animals were trained first in an orientation task in which they were required to fixate directly ahead and then orient to stimuli introduced at various eccentricities throughout the visual field. They did not display the characteristic ipsilesional head and neck asymmetries and/or spontaneous ipsiversive rotational behaviors or show the profound contralesional visual neglect seen postoperatively in nonpretreated control animals. Rather, pretreated animals were able to orient to visual stimuli in the contralesional hemifield immediately following surgical recovery. Postmortem histology revealed severe retrograde degeneration of the ipsilesional lateral geniculate nucleus in both experimental groups, suggesting that postlesion visuomotor behavioral competencies in pretreated animals are attributable to preserved function in nongeniculocortical visual pathways. These observations are consistent with the hypothesis that visual cortex lesions normally induce secondary alterations via NMDA-mediated excitotoxicity in these other pathways that prevents them from supporting visuomotor behaviors. The similar behavioral competencies of MK-801pretreated animals and those whose lesion-induced deficits are ameliorated by removing basal ganglia afferents to the ipsilesional superior colliculus are consistent with this hypothesis and highlight the normal functional capabilities of this circuit. It is likely that MK-801 pretreatment acts, at least in part, by preserving the normal interhemispheric control dynamics with which the basal ganglia influence superior colliculus-mediated orientation behaviors.

\section{Introduction}

Unilateral removal of all primary and contiguous regions of visual cortex in cats produces a profound deficit in their ability to orient to contralesional visual cues (Sprague and Meikle, 1965; Sprague, 1966; Sherman, 1974, 1977; Wallace et al., 1989, 1990). The animals behave as if they are unaware of objects in visual space contralateral to the lesion. Remarkably, this visual hemineglect can be ameliorated with a second lesion made in either the opposite superior colliculus (SC) or in the anterior aspect of the opposite substantia nigra, pars reticulata $(\mathrm{SNr})$. Either midbrain lesion effectively severs crossed basal ganglia outputs via nigrocollicular afferents en route to the SC ipsilateral to the damaged cortex (Wallace et al., 1989, 1990). These observations indicate that the remaining ipsilesional neural architecture has both the capacity to detect visual stimuli and to select appropriate motor programs to respond to them in the neglected hemifield. However, it is actively prevented from doing so by inhibitory processes that emanate from the opposite basal ganglia via crossed nigrocollicular projections.

The unique physiological properties of these crossed nigrocollicular projections provide one component of a pair of comple-

Received July 5, 2008; revised March 10, 2009; accepted April 20, 2009.

This work was supported by the National Institutes of Health (Grant NS35008 to J.G.M. and Grants NS36916 and EY016716 to B.E.S.) and a grant from the Harry 0. Parker Neurosciences Research Fund.

Correspondence should be addressed to John G. McHaffie, Department of Neurobiology and Anatomy, Wake Forest University School of Medicine, Winston-Salem, NC 27157. E-mail: mchaffie@wfubmc.edu.

DOI:10.1523/JNEUROSCI.3125-08.2009

Copyright $\odot 2009$ Society for Neuroscience $\quad$ 0270-6474/09/296917-09\$15.00/0 mentary circuits that the basal ganglia use for the interhemispheric coordination of visuomotor behaviors (Jiang et al., 2003). Presumably, the dynamic interplay between basal ganglia circuits that mediate focal disinhibition of the ipsilateral SC (via uncrossed nigrocollicular projections) and global inhibition of its contralateral counterpart (by crossed nigrocollicular fibers) is altered by large visual cortex lesions. The effect is to render the ipsilesional SC functionally inoperative. These observations suggest that the cortical lesion has dual effects: a primary and immediate effect that results in the loss of all functions directly attributed to visual cortex itself, and a cascade of secondary alterations that render its ipsilateral midbrain target, the SC, inoperative.

These secondary alterations may be initiated by lesioninduced glutamate excitotoxicity. Glutamate excitotoxicity mediated via NMDA receptors is known to be an important contributor to deficits associated with cerebral ischemia and traumatic brain injury (Faden et al., 1989; Obrenovitch and Urenjak, 1997; Dirnagl et al., 1999; Lee et al., 1999). It can produce secondary alterations in structures far removed from the original insult site and, perhaps, in structures that are not even directly connected with the damaged area. If such secondary alterations are involved in the orientation deficits that follow visual cortex removal, then agents that selectively block NMDA receptors might mitigate these effects and preclude this consequent behavioral deficit. One such agent, the noncompetitive glutamate antagonist dizocilpine (MK-801), has been shown to enhance posttraumatic behavioral capabilities in experimental animals performing a variety of tasks (Bullock and Fujisawa, 1992; McIntosh, 1994; McIntosh et al., 


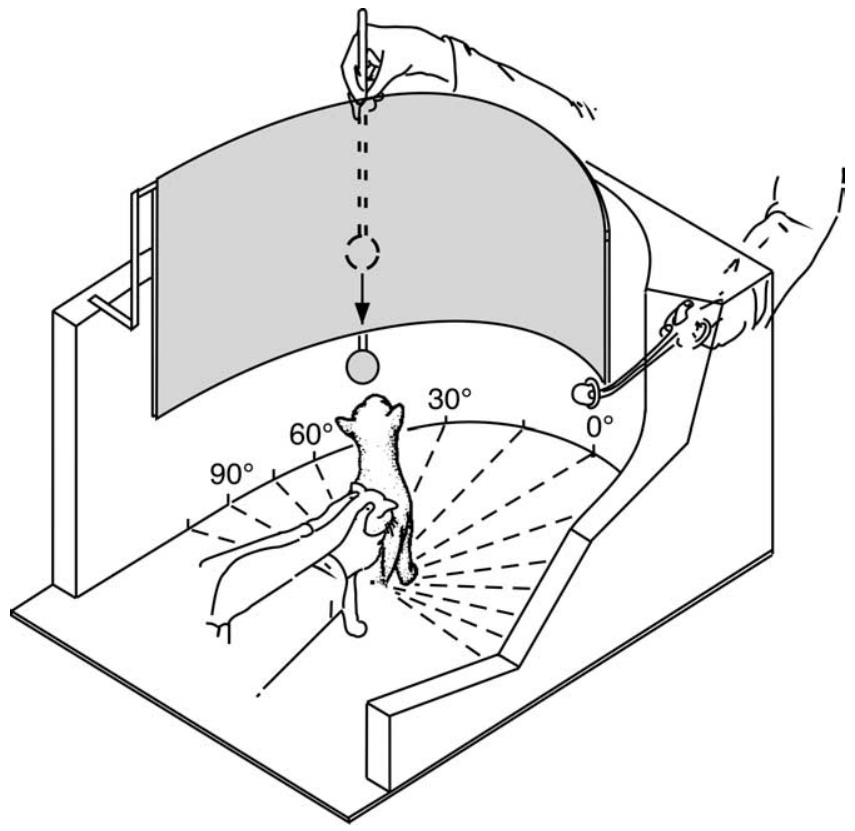

Figure 1. Each cat was trained to fixate on a morsel of food presented at eye-level directly ahead $\left(0^{\circ}\right)$. When released from restraint, it moved briskly forward toward the food reward. On select trials, a ping-pong ball at the end of a rod was introduced from behind a curtain at one of 14 equally spaced radial positions ( $105^{\circ}$ left to $105^{\circ}$ right), coincident with the animal's release. A food reward was given when the animal either oriented to the ping-pong ball or moved to the fixation point if no stimulus was presented (or detected). A food reward was given when the animal either oriented to the ping-pong ball or, if no stimulus was presented (or detected), it moved to the fixation point.

1996). Testing this possibility was the objective of the present study.

\section{Materials and Methods}

Nine mature domestic cats of either sex, obtained from a USDA-licensed commercial animal breeding facility (Liberty Labs), were used in the present study. All experimental procedures were performed in compliance with the National Institutes of Health (NIH) Guide for the Care and Use of Laboratory Animals (NIH Publications No. 80-23, revised 1996) and approved by the Institutional Animal Care and Use Committee at Wake Forest University School of Medicine. All efforts were made to minimize the number of animals used and to alleviate any discomfort.

Visual orientation testing procedures. Visual orientation was evaluated using previously applied methods (Hardy and Stein, 1988). Testing was conducted in a semicircular orientation arena. The arena was subdivided into $15^{\circ}$ sectors, extending from $105^{\circ}$ left to $105^{\circ}$ right. Visual test stimuli (a white ping-pong ball on the end of a wand) were delivered manually, emerging from behind a black curtain hung parallel to the black arena walls. This arrangement, depicted in Figure 1, minimized extraneous visual cues associated with stimulus delivery and eliminated anticipatory movements. The apparatus was housed in a standard laboratory environment with normal ambient light and sound levels $(\sim 31 \mathrm{~dB}, S P L)$. A food-restricted cat was gently restrained by an animal handler so that its head and eyes were directed toward the $0^{\circ}$ fixation mark, $58 \mathrm{~cm}$ away. The handler was blind to the location of test stimuli to preclude him from inadvertently providing the animal with target-related cues. Each cat was trained to fixate directly ahead on a food reward held in a pair of forceps that protruded through a hole in the forward wall of the apparatus. A trial began when the experimenter, who also was monitoring the animal's head/eye position, determined that the animal was fixating and gave the verbal command "Go." At that time the animal was released and could move toward the food reward. On some trials, visual test stimuli emerged from behind the curtain coincident with the Go command. If the animal oriented briskly toward the test stimulus, it received a food reward at that position. If the animal did not orient to test stimuli, or if no test stimuli were delivered (i.e., "catch" trials), it could move ahead to receive a food reward at the $0^{\circ}$ fixation mark. These quasirandomly presented catch trials effectively minimized "scanning" or spontaneous orientations (Wallace et al., 1989). Thus, the cat was rewarded regardless of its response and made few spontaneous responses. Test stimulus locations were assigned quasirandomly at $15^{\circ}$ eccentricities along the horizontal meridian throughout the field. Typically, each eccentricity was tested 4 times during a daily session. After a variable period of training, intact cats responded to stimulus delivery on nearly every trial, albeit with lowered accuracy at peripheral locations. Criterion performance was 95\% correct responses, averaged throughout the field.

Before each daily testing session, cats were food-restricted for $24 \mathrm{~h} \mathrm{but}$ had ad libitum access to water at all times. As a reward during training and testing, cats received $40 \mathrm{~g}$ of high caloric value food (Science Diet Kitten Original, Hill's Pet Nutrition) in the orientation arena and, following each session, were allowed to feed on the remainder of their daily ration while in the testing area. Body weight was monitored daily during the week, with no excessive weight loss noted. No testing was conducted on weekends, when the cats were permitted to feed ad libitum on a daily ration of standard animal chow.

After collecting a minimum of 100 normative tests at each eccentricity, an animal was prepared for unilateral visual cortex ablation, with or without MK-801 pretreatment (see below). If normative testing revealed a particular cat had a tendency toward better performance in one hemifield (generally reflected as greater accuracy in the periphery of that field), the visual cortex subserving that hemifield (i.e., contralateral) was selected for removal. Following cortical extirpation and surgical recovery, the presence, duration, and magnitude of any spontaneous circling and/or head deviation was noted and in some cases recorded on videotape. Once any postsurgical motor asymmetries had resolved, animals were retested on the visual orientation task.

Surgical procedures. All surgery was conducted aseptically. Animals were food-deprived for $24 \mathrm{~h}$ before surgery and administered a corticosteroidal anti-inflammatory (dexamethasone; $1 \mathrm{mg} / \mathrm{kg}$, i.m.) preoperatively to minimize cerebral edema. Sedation was induced with ketamine hydrochloride (20-30 mg/kg, i.m.), and a preoperative dose of an analgesic (butorphanol, 0.1-0.4 mg/kg, i.m.) was given. An endotracheal tube was inserted, and a surgical plane of anesthesia was induced with isoflurane $(1-4 \%)$. In some cases, nonpretreated cats were anesthetized with pentobarbital (22-30 mg/kg, i.p. or i.v.). Core body temperature, expiratory $\mathrm{CO}_{2}$, blood pressure, and heart rate were continuously monitored (VSM7, VetSpecs) and maintained within normal physiological bounds. Animals were placed in a stereotaxic head-holder, wrapped in a heating pad, and the saphenous vein catheterized. Pretreated animals received a dose of MK-801 (3 mg/kg, i.v.; dizocilpine maleate; SigmaAldrich) 30 min before cortical extirpation. A midline scalp incision was made, and a craniotomy exposed the cortical areas to be removed. The dura was reflected, and the cortical blood vessels were heat coagulated to minimize bleeding. The gray matter then was extirpated by subpial aspiration. The following cortical areas were removed: 17, 18, 19, 20a, 20b, 21a, 21b, DLS, VLS, PS, PMLS, PLLS, AMLS, ALLS, 5, 7, and SVA (Rosenquist, 1985). Moist gelfoam was placed within the aspiration defect, the cranial bone plate was replaced, and the scalp closed with sutures. An antiseptic agent was applied topically around the sutured wound margin, and the animal received an injection of a broadband antibiotic (cefazolin, $20 \mathrm{mg} / \mathrm{kg}$, i.m.). Physiological saline (50-200 ml, s.c. or i.v.) was given to compensate for fluid loss. The animal then was removed from the stereotaxic frame and placed in a darkened recovery cage.

The degree of neuroprotection is determined by drug concentrations not in the plasma but in specific brain areas vulnerable to injury at critical times during the trauma (Chen et al., 1991; Wallace et al., 1992). While we are unaware of data on the specifics pharmacokinetics and tissue binding of MK-801 in cats, the dose we employed (i.e., $3 \mathrm{mg} / \mathrm{kg}$, i.v., see above) is similar to that previously reported as efficacious in this species (Ozyurt et al., 1988; Miyabe et al., 1997). Given that MK-801 can quickly reach maximal concentrations in the brain within 10-30 min of injections (Vezzani et al., 1989; Wallace et al., 1992) and its brain uptake is dominated by the level of blood flow (Wallace et al., 1992), it is likely that 

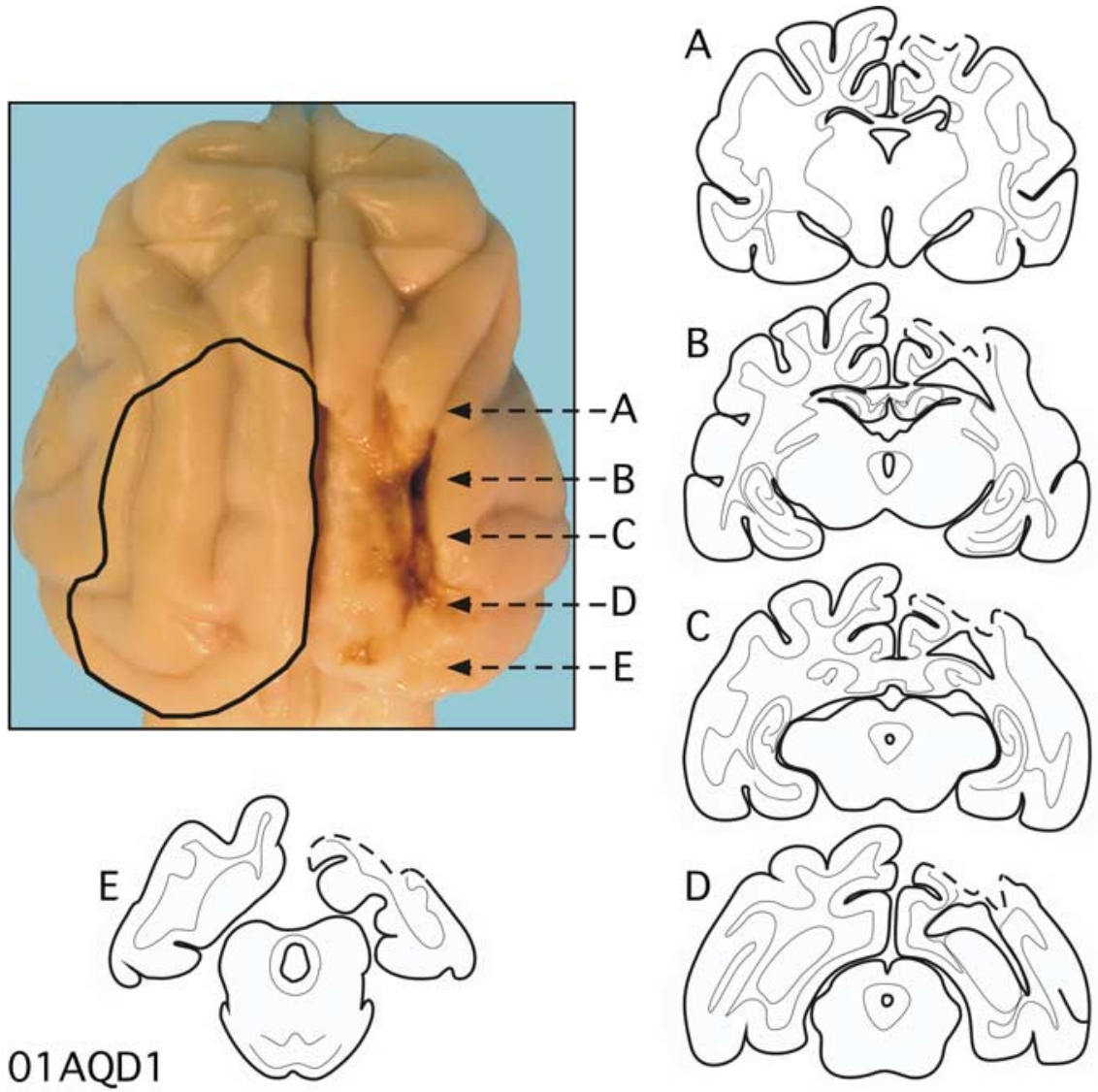

Figure 2. A whole-brain macrophotograph from a MK-801-pretreated cat reveals the extent of cortical tissue removal. Because the remaining cortex shifts medially to fill the aspiration defect, the actual extent of the lesion is minimized. The approximate extent of the lesion is outlined on the intact hemisphere. Five evenly spaced coronal sections $(\boldsymbol{A}-\boldsymbol{E})$ throughout the rostrocaudal extent of the lesion are shown. Dashed lines in these sections depict the extirpated tissue border. The behavior of this cat (01AQD1) is shown in Figure 4.

maximal brain concentrations would have been achieved before tissue extirpation and disruption of cortical blood flow.

Because of the long-term sedating effect of the drug, MK-801pretreated cats had significantly longer recovery times than nonpretreated animals and required considerable postoperative monitoring and maintenance while on the respirator. Observations were made every 30 min for the duration of the recovery period, which lasted from 12 to $48 \mathrm{~h}$. During this time, the animals' posture was adjusted, and vital functions monitored and maintained. Once alert and ambulatory, they were given a prophylactic dose of analgesic (butorphanol tartrate; $0.1-0.4 \mathrm{mg} / \mathrm{kg}$, i.m.) and antibiotic (cefazolin, $20 \mathrm{mg} / \mathrm{kg}$, i.m.) and returned to the home cage. Analgesics were continued for 18-24 h. Dexamethasone was administered, in progressively lower doses, for $5 \mathrm{~d}$, twice a day.

Histological evaluation of cortical lesions. After all data were collected, animals were sedated with ketamine $(20 \mathrm{mg} / \mathrm{kg}$, i.m.) and, following the loss of pinna reflexes, injected with lethal doses of pentobarbital (100 $\mathrm{mg} / \mathrm{kg}$; i.p.). They then were exsanguinated by transcardial perfusion with $0.9 \%$ saline followed by an aldehyde fixative. Brains were removed, photographed, cut on a cryostat, and processed using routine histological procedures. The extent of each cortical lesion was determined by charting the damage in serial coronal sections onto drawings made of intraoperative photographs of the intact hemisphere, following procedures outlined by Wallace et al. (1989). The reconstructed lesion then was compared with standard physiological and anatomical maps to assess the extent of the lesion (Rosenquist, 1985). Microscopic examination of neutral red-stained sections through the dorsal lateral geniculate nucleus (LGN) were conducted to determine the extent of retrograde degeneration (Sherman, 1977; Wallace et al., 1989) and quantified by calculating the reduction in total volume compared with the intact side.

\section{Results}

Consistent with previous observations (Sprague and Meikle, 1965; Sprague, 1966; Sherman, 1974, 1977; Wallace et al., 1989, 1990), all cats exhibited brisk orientation to visual stimuli between $105^{\circ}$ left and right of fixation before lesioning. Following cortical lesions, no behavioral performance differences were noted that could be ascribed to the particular hemisphere involved. Thus, the data here have been normalized for clarity to appear as if all lesions were made in the right cortex.

\section{Histological analysis}

Figure 2 illustrates a representative lesion reconstruction for one of the MK-801pretreated animals. In this, and every other case, approximately the posterior threefourths of both the lateral and suprasylvian gyri were completely removed along with some of the posterior ectosylvian gyrus. The gray matter of the medial aspect of the hemisphere posterior to the cruciate gyrus was removed above the splenial sulcus. In this, and in all other cases, the anterior ectosylvian sulcus (AES) was left intact, thereby sparing its visual and visualmultisensory representations (Mucke et al., 1982; Jiang et al., 1994a,b).

\section{Lesion effects on nonpretreated animals} Immediately following recovery from surgical anesthesia, all $(n=4)$ nonpretreated animals displayed marked tonic head deviation toward the side of the lesion and ipsiversive circling behavior. These motor biases resolved gradually over the following 2-5 d, but they prevented quantitative assessment of visual orientation during this time. However, neurological evaluation during this period revealed a lack of blink-to-threat reflex for contralesional stimuli, with no indication of orientation to either visual or auditory stimuli at any position within the contralesional hemifield. Responses to contralesional tactile stimuli were preserved. Contralesional auditory orientation deficits were present, but they resolved within the first posttrauma week. Blink-to-threat deficits and visual neglect remained.

Once ipsiversive circling had resolved, postsurgical quantitative behavioral testing revealed a profound contralesional visual orientation deficit in all animals (Fig. 3). The contralesional visual orientation deficits lasted through the subsequent testing periods, the longest of which was 68 weeks. The long-term nature of such deficits was previously described by Sprague (Sprague, 1966), who considered them permanent (Wallace et al., 1989). In contrast, no visual orientation deficits were present in the ipsilesional hemifield of any of these animals (Fig. 3, bottom). In fact, their overall behavioral performance to stimuli in the intact hemifield improved with subsequent testing, as there was a progressive decrease in number of missed responses to peripheral visual stimuli.

\section{Lesion effects on pretreated animals}

The visual performance of animals pretreated with MK-801 $(n=$ 5 ) was in striking contrast to that of their counterparts described 
above. There were far fewer motor anomalies present immediately following recovery from surgery and those that were noted were comparatively mild. Although the ipsilesional pupil was usually dilated for several days, tonic head deviations were either absent or just noticeable and lasted only a few days. Similarly, the duration of ipsiversive circling was minimal and was resolved within 1-2 d of surgery. Blink-to-threat reflexes in the contralesional field were preserved, and visual or auditory stimuli delivered in the contralesional hemifield evoked brisk orientation of the eyes, pinnae, head and body. In several cats, postsurgical recovery was so rapid that it was possible to begin quantitative behavioral testing the following day.

In no instance $(n=5)$ did immediate postsurgical testing reveal any contralesional visual orientation deficits (Fig. 4). Equivalently brisk responses were made to visual test stimuli presented in both the ipsilesional and contralesional visual hemifields, and no obvious kinematic impairments were evident in responses to contralesional visual stimuli. In every respect, visual orientation behaviors appeared to be normal and appeared too quickly to be attributable to the spontaneous recoveries that sometimes occur after 4-8 postoperative weeks (Wallace et al., 1989).

The sparing of visual orientation behavior occurred in these animals despite massive retrograde degeneration of the ipsilateral lateral geniculate nucleus (LGN). The histology of two such pretreated cats, whose behavior is depicted above, is illustrated in Figure 5. Reconstruction of the lesion revealed that virtually all regions of primary visual cortex and adjacent extraprimary visual cortex had been removed (cf., Fig. 2). Postmortem microscopic inspection of the thalamus confirmed that the LGN was severely damaged, with few remaining cell bodies and substantial collapse of its nuclear dimensions. Thus, it is likely that the residual visual capabilities in pretreated cats reflect nongeniculocortical function.

One of the MK-801-pretreated animals deviated from the pattern observed in the other 4 . Instead it failed to maintain the spared visual functions that were present during initial postsurgical tests. This animal showed a progressive decline in visual orientation responses as shown in Figure 6. It differed in other ways as well. Its recovery was far slower than that of others in this group, so that its first orientation tests could not take place until $8 \mathrm{~d}$ after surgery. Although the animal could orient in much of the contralesional hemifield, a large percentage of the time its performance fell far short of the postoperative capabilities of the other pretreated animals. During the ensuing weeks, its visual performance progressively declined until it was no longer able to orient to contralesional visual stimuli and its performance was indistin-
PRE-LESION BEHAVIOR
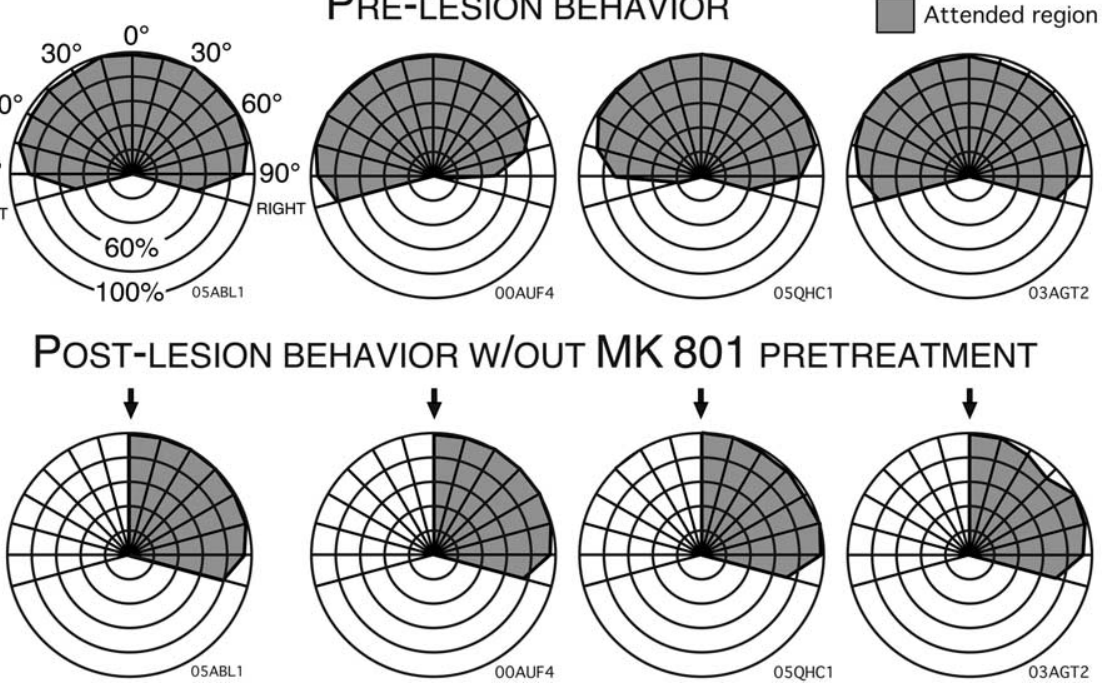

Figure 3. Large unilateral visual cortex lesions produce a profound visual orientation deficit in nonpretreated cats. Dark gray shaded areas of visual perimetry diagrams indicate correct responses seen at each tested position in each cat before (upper) and after (lower) cortical extirpation. The outer circle of the perimetry diagram represents $100 \%$ correct responses.

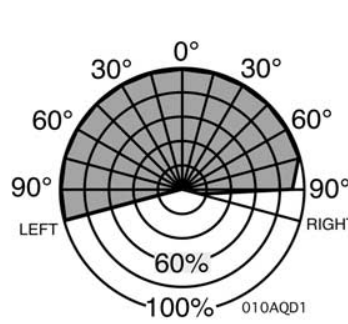

Pre-Lesion behaVior
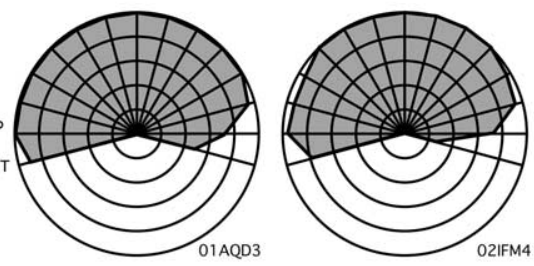

$021 F M 4$

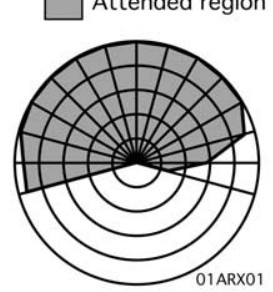

\section{H}
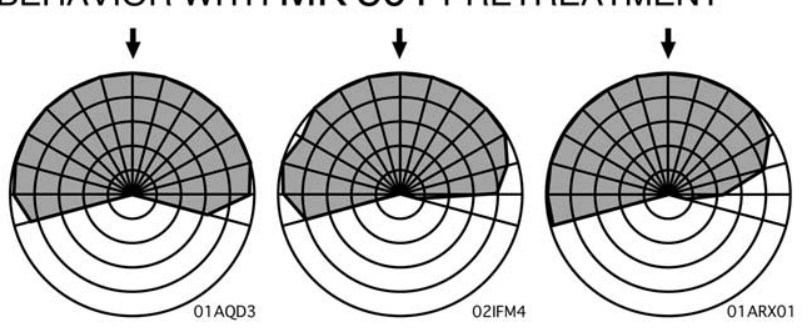

Figure 4. Pretreatment with the NMDA antagonist MK-801 prevents lesion-induced visual orientation deficits. Dark gray Note that the prelesion and postlesion orientation behavior was the same: the expected visuomotor deficits were absent. All cats were capable of normal visual orientation behaviors immediately following surgical recovery.

guishable from that of nonpretreated controls. The specific reasons for the performance differences of this animal were not immediately apparent from its behavioral training history, responsiveness or histological examination of its tissue.

\section{Discussion}

The present data reveal that the profound contralateral visual hemineglect produced by unilateral visual cortex lesions is prevented by pretreatment with the NMDA receptor antagonist MK-801. These findings support the hypothesis that such lesions induce secondary NMDA-mediated excitotoxic alterations that prevent the remaining subcortical structures from supporting visuomotor behaviors. It is not yet possible to evaluate the breadth of the brain structures (including the SC itself, thalamic tecto-recepient nuclei, etc) that were affected by this pretreat- 


\section{Contralesional LGN IPSILESIONAL LGN}
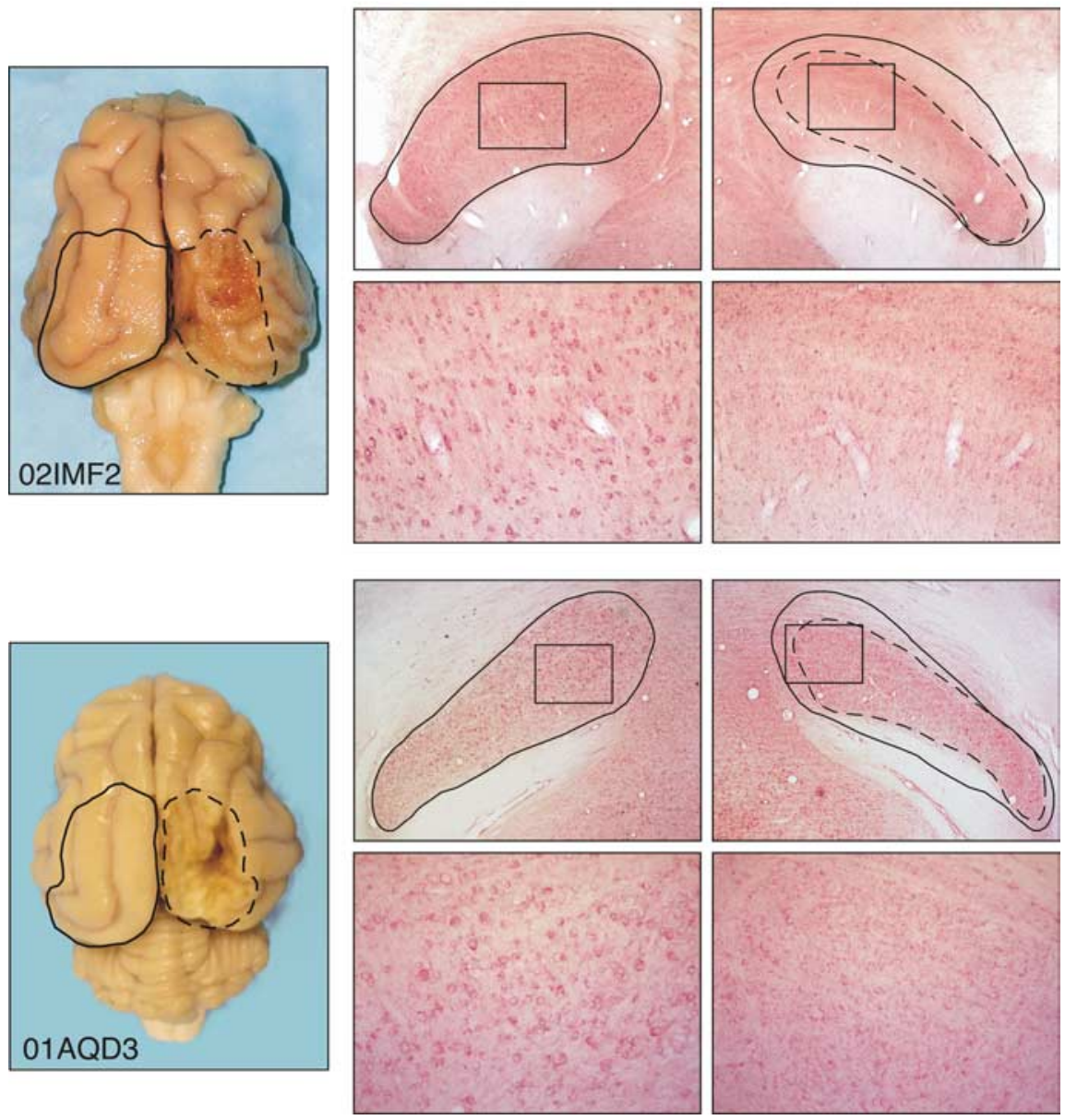

Figure 5. Pretreatment with MK-801 prevented visual orientation deficits despite massive retrograde degeneration of the ipsilesional lateral geniculate nucleus. Postmortem analysis in two MK-801-pretreated animals reveals the extent of cortical damage (left) and corresponding pairs of neutral red stained sections in the contralesional and ipsilesional LGN (right). Dashed outline shows the reduction in nuclear size, and area in box is show at higher magnification. Note the lack of stained cell bodies in the ipsilesion LGN and the collapse of nuclear borders. Thus, while MK-801 pretreatment preserved visual orientation capabilities, it did not prevent retrograde degeneration in the lateral geniculate nucleus. It is likely, therefore, that any residual visual capabilities cannot be ascribed to an intact geniculocortical system.

ment procedure. However, one parsimonious explanation is that pretreatment minimized lesion-induced alterations within the basal ganglia-SC circuit, thereby preserving the normal interhemispheric dynamics by which the basal ganglia bilaterally regulate SC activity.

\section{Neurological dysfunction as a two-stage process}

The pathophysiology underlying lesion-induced deficits arise by two distinct processes. Primary effects of injury are due to immediate physical disruption of tissue and the loss of its associated neural circuitry. Secondary effects evolve as a consequence of the release of excess glutamate into structures targeted by the damaged region. The resultant NMDA receptor-mediated calcium influx can kill its constituent neurons or compromise their normal function due to biochemical sequelae triggered by high intracellular calcium (Rothman and Olney, 1986; Choi et al., 1987; Choi, 1988; Choi and Rothman, 1990). As originally articulated by von Monakow (von Monakow, 1914; Feeney and Baron, 1986), these secondary alterations can cause functional disruption of structures remote from the initial injury but related to it via multisynaptic circuits. Administration before cortical extir- pation ensured that MK-801 was bound to receptors before any pathological glutamate release. It is likely, however, that posttraumatic delivery within a restricted temporal window also may be effective, as MK-801 enhances posttrauma behavioral capabilities (McIntosh et al., 1989, 1996; Bullock and Fujisawa, 1992).

\section{A distributed network underlies visual orientation}

Although the SC plays a central role in visual orientation (Stein and Meredith, 1993; May, 2006), it is dependent on integrated inputs from both the basal ganglia and visual cortex. Deep SC neurons effecting visual orientation via connections to the brainstem and spinal cord (Stein and Meredith, 1993; May, 2006) receive visual cortex projections (Rosenquist, 1985; Harting et al., 1992) necessary for normal visual activity (Ogasawara et al., 1984; Hardy and Stein, 1988). Similarly, these same SC neurons receive GABAergic inputs from basal ganglia output pathways (Chevalier et al., 1984; May and Hall, 1984; Chevalier et al., 1985; Harting et al., 1988) that modulate both their sensory (Chevalier et al., 1984, 1985) and motor (Hikosaka and Wurtz, 1983; Joseph and Boussaoud, 1985) activity. Thus, it is likely that the preservation of visual orientation in pretreated animals is due, in large part, to the retention of functional integrity within this basal ganglia-SC network.

\section{The striatum as a site of excitotoxicity}

The basal ganglia are particularly vulnerable to excitotoxic damage. The major input structure of the basal ganglia, the striatum, receives glutamatergic input from widespread regions of the cortex. Corticostriatal interactions are highly plastic and mediated via NMDA receptors (Calabresi et al., 1996). Damage to nonvisual cortex is known to produce secondary striatal alterations (Schallert et al., 1990; Jones and Schallert, 1992; Hara et al., 1993; Hoffman et al., 1994; Hoane et al., 1997), and posttrauma administration of NMDA antagonists reduces the degree of these alterations (Gill et al., 1987; Barth et al., 1990; Hara et al., 1993; Feldman et al., 1996; Hoane et al., 1998), facilitating behavioral recovery (McIntosh et al., 1989; Barth et al., 1990; Hoane et al., 1997, 1998).

Similar events likely follow visual cortex lesions. Visual cortex, especially those extrastriate regions whose disruption produces visual neglect (Hardy and Stein, 1988; Payne et al., 1996), sends dense excitatory projections to the striatum (Norita et al., 1991; McHaffie et al., 1993; Niida et al., 1997). That such lesions alter the internal milieu of the striatum is suggested by the presence of ipsiversive circling following visual cortex lesions (Sprague and Meikle, 1965; Wallace et al., 1989, 1990). This transient phenomenon is associated with the development of asymmetries in striatal dopaminergic receptor subtypes (Glick et al., 1988) which is thought to alter the activity of SNr neurons (Weick and Walters, 1987; Jaspers et al., 1989; Rohlfs et al., 1997), presumably includ- 
ing those that project to the SC. Furthermore, excitotoxic lesions of the striatum produce sequential metabolic alterations at the level of the SNr and SC that lead to behavioral alterations (Jaspers et al., 1989).

\section{Basal ganglia control of SC-mediated visuomotor behaviors}

Although SNr afferents to the SC are bilateral (Beckstead et al., 1981; Harting et al., 1988), the more numerous ipsilateral projections (Beckstead et al., 1981; Gerfen et al., 1982) are the most thoroughly studied. Uncrossed $\mathrm{SNr}$ neurons have relatively small visual receptive fields that are in topographic register with those of their ipsilateral SC target neurons. Their high spontaneous activity is phasically inhibited by visual stimuli (Hikosaka and Wurtz, 1983; Chevalier et al., 1984, 1985; Joseph and Boussaoud, 1985; Jiang et al., 2003), thereby disinhibiting their SC targets, which in turn mediate contralaterally directed visuomotor behaviors. Crossed $\mathrm{SNr}$ neurons have distinctly different physiological properties (Jiang et al., 2003): they have large receptive fields in the hemifield opposite those of their contralateral SC

target neurons and display relatively low spontaneous activity that is phasically excited by visual stimuli. Because their axon terminals are broadly distributed in the SC (Jiang et al., 2003; Gabriele et al., 2007), they facilitate global inhibition. Given that cortical perturbations preferentially affect striatal cells of origin of the indirect pathway (Berretta et al., 1997; Parthasarathy and Graybiel, 1997), which increases basal ganglia output activity (Mink, 1996), the net consequences of cortical lesions might be increased activation of crossed output neurons.

\section{A "simple" physiological model}

We suggest that cortically induced visual hemineglect is produced by NMDA-mediated excitotoxic events in the striatum that alter transbasal basal ganglia pathways. This ultimately compromises the functional integrity of the ipsilesional SC by upregulating the spontaneous activity of crossed nigrocollicular neurons (Fig. 7). Consequently, their normal widespread phasic inhibitory role (Jiang et al., 2003) is transformed to one of widespread tonic inhibition, preventing the ipsilesional SC from mediating visual orientation. Such changes are analogous to basal ganglia alterations that account for hypokinetic or akinetic dysfunction associated with Parkinson's disease (DeLong, 1990; Albin et al., 1995).

This hypothesis also provides a physiological basis for the Sprague Effect, a paradoxical phenomena whereby visuomotor deficits induced by visual cortical lesions are ameliorated by a second lesion of the contralesional SC (Sprague, 1966; Sherman, 1974, 1977) or SNr (Wallace et al., 1989, 1990). Thus, a presumptive source of pathophysiological inhibition is eliminated by severing crossed $\mathrm{SNr}$ axons as they pass through the contralesional SC en route to the SC ipsilateral to the damaged cortex. This facilitates ipsilesional SC activity, rendering it responsive to previously ineffectual visual inputs and capable of once again supporting visual orientation. The observation that ipsilesional SC bicuculline injections temporarily ameliorates hemineglect (Ciaramitaro et al., 1997b), but lesions of the ipsilesional SNr do not (Ciaramitaro et al., 1997a), underscores the specific contribution of the crossed GABAergic projection.

Precisely how unilateral lesions induce contralesional basal ganglia alterations is not yet clear. Anatomical data indicate that crossed nigrothalamic neurons only become evident following unilateral cortical lesions and a period of lesion-induced circling (Pritzel and Huston, 1981; Neumann et al., 1982). This suggests that normally quiescent crossed neurons are poor transporters of retrograde tracers and are effectively "invisible" to anatomical techniques until rendered tonically active by cortical perturbations. Interestingly, manually delaying circling behavior also delays these anatomical changes (Morgan et al., 1983). Since nigrothalamic neurons often have collaterals to the SC (Anderson and Yoshida, 1977, 1980), crossed nigrocolliculus neurons may be similarly affected. It is not yet possible, however, to eliminate the possibility that the activity changes induced in this pathway are secondary to changes induced in the SC itself. Clearly, further experiments detailing striatum and SC alterations as well as direct electrophysiological evidence from the crossed neurons are necessary to confirm this hypothesis.

The source of visual input that facilitates SC-mediated orientation in the absence of cortex is another critical question. One obvious route is via direct monosynaptic retinal projections to the deep SC (Beckstead and Frankfurter, 1983), which, although modest, can activate deep SC neurons (Berson and McIlwain, 1982). Another possibility is via descending projections from the superficial SC, which retains its visual activity following visual cortex lesions (Wickelgren and Sterling, 1969; Rosenquist and Palmer, 1971; Ogasawara et al., 1984) because of direct retinal input (Kanaseki and Sprague, 1974; Harting and Guillery, 1976). Superficial layer SC activity has both monosynaptic and polysynaptic access to deep SC neurons (Lee et al., 1997; Doubell et al., 


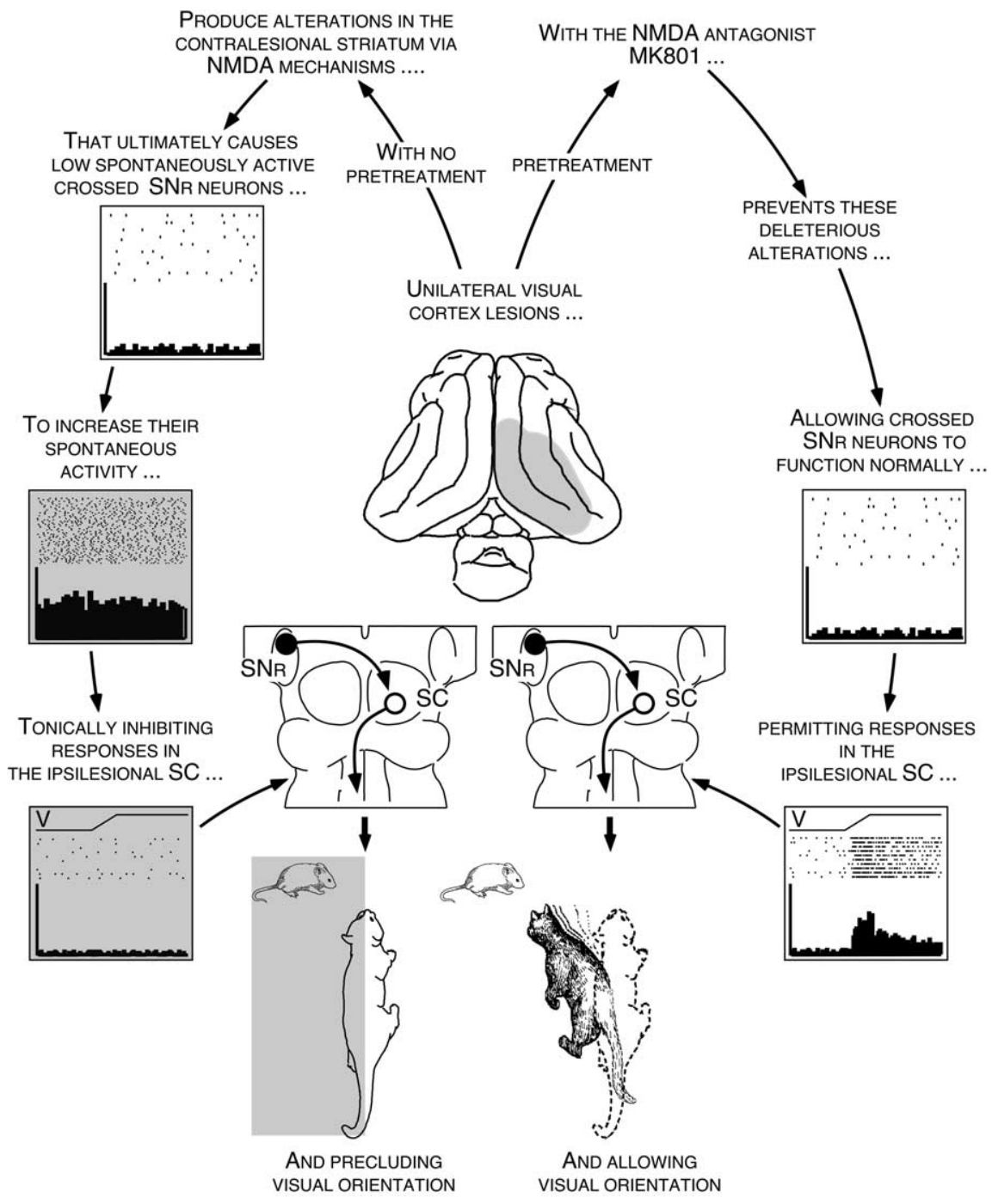

Figure 7. We suggest that the cortical lesions induce a persistence contralateral visual field defect because secondary NMDAmediated excitotoxic events in the basal ganglia ultimately upregulate the normally low spontaneous activity of crossed nigrocollicular neurons. This changes their functional role from one of phasic global inhibition to one of tonic global suppression of their target SC and prevents SC-mediated visuomotor behaviors.

2003), a route thought to mediate short-latency express saccades (Lee et al., 1997). Another potential route is the SC-basal ganglia-SC loop (May and Hall, 1986; McHaffie et al., 2005). Here ascending projections from the superficial SC layers convey visual information to the striatum via the thalamus (Harting et al., 2001a, 2001b), and descending striatal outputs regulate deep SC neurons via SNr projections (Chevalier et al., 1985; Harting et al., 1988). This closed-looped architecture provides the means for detecting and localizing visual stimuli, as well as for selecting and coordinating the appropriate motor programs required for orienting (McHaffie et al., 2005).

These data raise the possibility that other visual capabilities are present in pretreated animals. Although hemineglect animals whose deficits have been ameliorated by midbrain lesions still lack visual discrimination abilities (Loop and Sherman, 1977), the postlesional behaviors of pretreated animals might be more sophisticated than the orientation tasks employed here revealed. This notion finds support in recent evidence indicating that superficial SC neurons possess basic feature analysis properties in the absence of visual cortex (Girman and Lund, 2007). If so, any residual visual discrimination capacity would provide important insights into the subcortical architecture that subserve blindsight (Stoerig and Cowey, 1997; Ptito et al., 2001).

\section{References}

Albin RL, Young AB, Penney JB (1995) The functional anatomy of disorders of the basal ganglia. Trends Neurosci 18:63-64.

Anderson M, Yoshida M (1977) Electrophysiological evidence for branching nigral projections to the thalamus and the superior colliculus. Brain Res 137:361-364.

Anderson ME, Yoshida M (1980) Axonal branching patterns and location of nigrothalamic and nigrocollicular neurons in the cat. J Neurophysiol 43:883-895.

Barth TM, Grant ML, Schallert T (1990) Effects of MK-801 on recovery from sensorimotor cortex lesions. Stroke 21:III153-III157.

Beckstead RM, Frankfurter A (1983) A direct projection from the retina to the intermediate gray layer of the superior colliculus demonstrated by anterograde transport of horseradish peroxidase in monkey, cat and rat. Exp Brain Res 52:261-268.

Beckstead RM, Edwards SB, Frankfurter A (1981) A comparison of the intranigral distribution of nigrotectal neurons labelled with horseradish peroxidase in the monkey, cat, and rat. J Neurosci 1:121-125.

Berretta S, Parthasarathy HB, Graybiel AM (1997) Local release of GABAergic inhibition in the motor cortex induces immediate-early gene expression in indirect pathway neurons of the striatum. J Neurosci 17:4752-4763.

Berson DM, McIlwain JT (1982) Retinal Y-cell activation of deep-layer cells in superior colliculus of the cat. J Neurophysiol 47:700-714.

Bullock R, Fujisawa H (1992) The role of glutamate antagonists for the treatment of CNS injury. J Neurotrauma 9 [Suppl 2]:S443-S462.

Calabresi P, Pisani A, Mercuri NB, Bernardi G (1996) The corticostriatal projection: from synaptic plasticity to dysfunctions of the basal ganglia. Trends Neurosci 19:19-24.

Chen M, Bullock R, Graham DI, Frey P, Lowe D, McCulloch J (1991) Evaluation of a competitive NMDA antagonist (D-CPPene) in feline focal cerebral ischemia. Ann Neurol 30:62-70.

Chevalier G, Vacher S, Deniau JM (1984) Inhibitory nigral influence on tectospinal neurons, a possible implication of basal ganglia in orienting behaviour. Exp Brain Res 53:320-326.

Chevalier G, Vacher S, Deniau JM, Desban M (1985) Disinhibition as a basic process in the expression of striatal function. I. The striato-nigral influence on tecto-spinal/tecto-diencephalic neurons. Brain Res 334:215-226.

Choi DW (1988) Glutamate neurotoxicity and diseases of the nervous system. Neuron 1:623-634.

Choi DW, Rothman SM (1990) The role of glutamate neurotoxicity in hypoxic-ischemic neuronal death. Annu Rev Neurosci 13:171-182.

Choi DW, Maulucci-Gedde M, Kriegstein AR (1987) Glutamate neurotoxicity in cortical cell culture. J Neurosci 7:357-368.

Ciaramitaro VM, Wallace SF, Rosenquist AC (1997a) Ibotenic acid lesions of the substantia nigra pars reticulata ipsilateral to a visual cortical lesion fail to restore visual orienting responses in the cat. J Comp Neurol 377:596-610.

Ciaramitaro VM, Todd WE, Rosenquist AC (1997b) Disinhibition of the superior colliculus restores orienting to visual stimuli in the hemianopic field of the cat. J Comp Neurol 387:568-587.

DeLong MR (1990) Primate models of movement disorders of basal ganglia origin. Trends Neurosci 13:281-285.

Dirnagl U, Iadecola C, Moskowitz MA (1999) Pathobiology of ischaemic stroke: an integrated view. Trends Neurosci 22:391-397. 
Doubell TP, Skaliora I, Baron J, King AJ (2003) Functional connectivity between the superficial and deeper layers of the superior colliculus: an anatomical substrate for sensorimotor integration. J Neurosci 23:6596-6607.

Faden AI, Demediuk P, Panter SS, Vink R (1989) The role of excitatory amino acids and NMDA receptors in traumatic brain injury. Science 244:798-800.

Feeney DM, Baron JC (1986) Diaschisis. Stroke 17:817-830.

Feldman Z, Gurevitch B, Artru AA, Oppenheim A, Shohami E, Reichenthal E, Shapira Y (1996) Effect of magnesium given 1 hour after head trauma on brain edema and neurological outcome. J Neurosurg 85:131-137.

Gabriele ML, Shahmoradian SH, French CC, Henkel CK, McHaffie JG (2007) Early segregation of layered projections from the lateral superior olivary nucleus to the central nucleus of the inferior colliculus in the neonatal cat. Brain Res 1173:66-77.

Gerfen CR, Staines WA, Arbuthnott GW, Fibiger HC (1982) Crossed connections of the substantia nigra in the rat. J Comp Neurol 207:283-303.

Gill R, Foster AC, Woodruff GN (1987) Systemic administration of MK-801 protects against ischemia-induced hippocampal neurodegeneration in the gerbil. J Neurosci 7:3343-3349.

Girman SV, Lund RD (2007) Most superficial sublamina of rat superior colliculus: neuronal response properties and correlates with perceptual figure-ground segregation. J Neurophysiol 98:161-177.

Glick SD, Lyon RA, Hinds PA, Sowek C, Titeler M (1988) Correlated asymmetries in striatal D1 and D2 binding: relationship to apomorphineinduced rotation. Brain Res 455:43-48.

Hara H, Harada K, Sukamoto T (1993) Chronological atrophy after transient middle cerebral artery occlusion in rats. Brain Res 618:251-260.

Hardy SC, Stein BE (1988) Small lateral suprasylvian cortex lesions produce visual neglect and decreased visual activity in the superior colliculus. J Comp Neurol 273:527-542.

Harting JK, Guillery RW (1976) Organization of retinocollicular pathways in the cat. J Comp Neurol 166:133-144.

Harting JK, Huerta MF, Hashikawa T, Weber JT, Van Lieshout DP (1988) Neuroanatomical studies of the nigrotectal projection in the cat. J Comp Neurol 278:615-631.

Harting JK, Updyke BV, Van Lieshout DP (1992) Corticotectal projections in the cat: anterograde transport studies of twenty-five cortical areas. J Comp Neurol 324:379-414.

Harting JK, Updyke BV, Van Lieshout DP (2001a) Striatal projections from the cat visual thalamus. Eur J Neurosci 14:893-896.

Harting JK, Updyke BV, Van Lieshout DP (2001b) The visual-oculomotor striatum of the cat: functional relationship to the superior colliculus. Exp Brain Res 136:138-142.

Hikosaka O, Wurtz RH (1983) Visual and oculomotor function of monkey substantia nigra pars reticulata. IV. Relation of substantia nigra to superior colliculus. J Neurophysiol 49:1285-1301.

Hoane MR, Raad C, Barth TM (1997) Non-competitive NMDA antagonists and anti-oxidant drugs reduce striatal atrophy and facilitate recovery of function following lesions of the rat cortex. Restor Neurol Neurosci 11:71-82.

Hoane MR, Irish SL, Marks BB, Barth TM (1998) Preoperative regimens of magnesium facilitate recovery of function and prevent subcortical atrophy following lesions of the rat sensorimotor cortex. Brain Res Bull 45:45-51.

Hoffman SW, Fülöp Z, Stein DG (1994) Bilateral frontal cortical contusion in rats: behavioral and anatomic consequences. J Neurotrauma 11:417-431.

Jaspers RM, Berkelbach van der Sprenkel JW, Cools AR (1989) Progressive pathology of the caudate nucleus, the substantia nigra pars reticulata and the deeper layers of the colliculus superior: acute behavioural and metabolic effects of intrastriatal kainic acid. Neuroscience 28:159-169.

Jiang H, Lepore F, Ptito M, Guillemot JP (1994a) Sensory interactions in the anterior ectosylvian cortex of cats. Exp Brain Res 101:385-396.

Jiang H, Lepore F, Ptito M, Guillemot JP (1994b) Sensory modality distribution in the anterior ectosylvian cortex (AEC) of cats. Exp Brain Res 97:404-414.

Jiang H, Stein BE, McHaffie JG (2003) Opposing basal ganglia processes shape midbrain visuomotor activity bilaterally. Nature 423:982-986.

Jones TA, Schallert T (1992) Subcortical deterioration after cortical damage: effects of diazepam and relation to recovery of function. Behav Brain Res 51:1-13.
Joseph JP, Boussaoud D (1985) Role of the cat substantia nigra pars reticulata in eye and head movements. 1. Neural activity. Exp Brain Res 57:286-296.

Kanaseki T, Sprague JM (1974) Anatomical organization of pretectal nuclei and tectal laminae in the cat. J Comp Neurol 158:319-337.

Lee JM, Zipfel GJ, Choi DW (1999) The changing landscape of ischaemic brain injury mechanisms. Nature 399:A7-14.

Lee PH, Helms MC, Augustine GJ, Hall WC (1997) Role of intrinsic synaptic circuitry in collicular sensorimotor integration. Proc Natl Acad Sci U S A 94:13299-13304.

Loop MS, Sherman SM (1977) Visual discriminations of cats with cortical and tectal lesions. J Comp Neurol 174:79-88.

May PJ (2006) The mammalian superior colliculus: laminar structure and connections. Prog Brain Res 151:321-378.

May PJ, Hall WC (1984) Relationships between the nigrotectal pathway and the cells of origin of the predorsal bundle. J Comp Neurol 226:357-376.

May PJ, Hall WC (1986) The sources of the nigrotectal pathway. Neuroscience 19:159-180.

McHaffie JG, Norita M, Dunning DD, Stein BE (1993) Corticotectal relationships: direct and "indirect" corticotectal pathways. Prog Brain Res 95:139-150.

McHaffie JG, Stanford TR, Stein BE, Coizet V, Redgrave P (2005) Subcortical loops through the basal ganglia. Trends Neurosci 28:401-407.

McIntosh TK (1994) Neurochemical sequelae of traumatic brain injury: therapeutic implications. Cerebrovasc Brain Metab Rev 6:109-162.

McIntosh TK, Vink R, Soares H, Hayes R, Simon R (1989) Effects of the $\mathrm{N}$-methyl-D-aspartate receptor blocker MK-801 on neurologic function after experimental brain injury. J Neurotrauma 6:247-259.

McIntosh TK, Smith DH, Garde E (1996) Therapeutic approaches for the prevention of secondary brain injury. Eur J Anaesthesiol 13:291-309.

Mink JW (1996) The basal ganglia: focused selection and inhibition of competing motor programs. Prog Neurobiol 50:381-425.

Miyabe M, Kirsch JR, Nishikawa T, Koehler RC, Traystman RJ (1997) Comparative analysis of brain protection by $\mathrm{N}$-methyl-D-aspartate receptor antagonists after transient focal ischemia in cats. Crit Care Med 25:1037-1043.

Morgan S, Huston JP, Pritzel M (1983) Effects of reducing sensory-motor feedback on the appearance of crossed nigro-thalamic projections and recovery from turning induced by unilateral substantia nigra lesions. Brain Res Bull 11:721-727.

Mucke L, Norita M, Benedek G, Creutzfeldt O (1982) Physiologic and anatomic investigation of a visual cortical area situated in the ventral bank of the anterior ectosylvian sulcus of the cat. Exp Brain Res 46:1-11.

Neumann S, Pritzel M, Huston JP (1982) Plasticity of cortico-thalamic projections and functional recovery in the unilateral detelencephalized infant rat. Behav Brain Res 4:377-388.

Niida T, Stein BE, McHaffie JG (1997) Response properties of corticotectal and corticostriatal neurons in the posterior lateral suprasylvian cortex of the cat. J Neurosci 17:8550-8565.

Norita M, McHaffie JG, Shimizu H, Stein BE (1991) The corticostriatal and corticotectal projections of the feline lateral suprasylvian cortex demonstrated with anterograde biocytin and retrograde fluorescent techniques. Neurosci Res 10:149-155.

Obrenovitch TP, Urenjak J (1997) Is high extracellular glutamate the key to excitoxicity in traumatic brain injury? J Neurotrauma 14:677-698.

Ogasawara K, McHaffie JG, Stein BE (1984) Two visual corticotectal systems in cat. J Neurophysiol 52:1226-1245.

Ozyurt E, Graham DI, Woodruff GN, McCulloch J (1988) Protective effect of the glutamate antagonist, MK-801 in focal cerebral ischemia in the cat. J Cereb Blood Flow Metab 8:138-143.

Parthasarathy HB, Graybiel AM (1997) Cortically driven immediate-early gene expression reflects modular influence of sensorimotor cortex on identified striatal neurons in the squirrel monkey. J Neurosci 17:2477-2491.

Payne BR, Lomber SG, Geeraerts S, van der Gucht E, Vandenbussche E (1996) Reversible visual hemineglect. Proc Natl Acad Sci USA 93:290-294.

Pritzel M, Huston JP (1981) Unilateral ablation of telencephalon induces appearance of contralateral cortical and subcortical projections to thalamic nuclei. Behav Brain Res 3:43-54.

Ptito A, Fortin A, Ptito M (2001) 'Seeing' in the blind hemifield following hemispherectomy. Prog Brain Res 134:367-378. 
Rohlfs A, Nikkhah G, Rosenthal C, Rundfeldt C, Brandis A, Samii M, Löscher W (1997) Hemispheric asymmetries in spontaneous firing characteristics of substantia nigra pars reticulata neurons following a unilateral 6-hydroxydopamine lesion of the rat nigrostriatal pathway. Brain Res 761:352-356.

Rosenquist AC (1985) Connections of visual cortical areas in the cat. In: Cerebral cortex (Peters A, Jones EG, eds), pp 81-117. New York: Plenum.

Rosenquist AC, Palmer LA (1971) Visual receptive field properties of cells of the superior colliculus after cortical lesions in the cat. Exp Neurol 33:629-652.

Rothman SM, Olney JW (1986) Glutamate and pathophysiology of hypoxic-ischemic brain damage. Ann Neurol 19:105-111.

Schallert T, Jones TA, Lindner MD (1990) Multilevel transneuronal degeneration after brain damage. Behavioral events and effects of anticonvulsant gamma-aminobutyric acid-related drugs. Stroke 21:III143-III146.

Sherman SM (1974) Visual fields of cats with cortical and tectal lesions. Science 185:355-357.

Sherman SM (1977) The effect of superior colliculus lesions upon the visual fields of cats with cortical ablations. J Comp Neurol 172:211-229.

Sprague JM (1966) Interactions of cortex and superior colliculus in mediation of visually guided behavior in the cat. Science 153:1544-1547.

Sprague JM, Meikle TH Jr (1965) The role of the superior colliculus in visually guided behavior. Exp Neurol 11:115-146.
Stein BE, Meredith AM (1993) The merging of the senses. Cambridge, MA MIT.

Stoerig P, Cowey A (1997) Blindsight in man and monkey. Brain 120:535-559.

Vezzani A, Serafini R, Stasi MA, Caccia S, Conti I, Tridico RV, Samanin R (1989) Kinetics of MK-801 and its effect on quinolinic acid-induced seizures and neurotoxicity in rats. J Pharmacol Exp Ther 249:278-283.

von Monakow C (1914) Die Lokalisation im Grobhirn und der Abbau der Funktion durch Kortikale Herde. Wiesbaden, Germany: Bergmann.

Wallace SF, Rosenquist AC, Sprague JM (1989) Recovery from cortical blindness mediated by destruction of nontectotectal fibres in the commissure of the superior colliculus in the cat. J Comp Neurol 284:429-450.

Wallace SF, Rosenquist AC, Sprague JM (1990) Ibotenic acid lesions of the lateral substantia nigra restore visual orientation behavior in the hemianopic cat. J Comp Neurol 296:222-252.

Wallace MC, Teasdale GM, McCulloch J (1992) Autoradiographic analysis of 3H-MK-801 (dizocilpine) in vivo uptake and in vitro binding after focal cerebral ischemia in the rat. J Neurosurg 76:127-133.

Weick BG, Walters JR (1987) Effects of D1 and D2 dopamine receptor stimulation on the activity of substantia nigra pars reticulata neurons in 6-hydroxydopamine lesioned rats: D1/D2 coactivation induces potentiated responses. Brain Res 405:234-246.

Wickelgren BG, Sterling P (1969) Influence of visual cortex on receptive fields in the superior colliculus of the cat. J Neurophysiol 32:16-23. 